\title{
A patient's view of diabetes
}

I first found out I had diabetes four weeks before Xmas. I was quite upset because I knew I would not be able to eat sweets and cakes etc. I think it was worse because it was so near Xmas and I usually have a lot of sweet things at Xmas. I didn't realise that I would never be able to eat normally again. I thought I would be able to eat anything except things with sugar in. I also did not realise that I would have to go into hospital.

The few days before I went into hospital, I felt tired and lazy, and I felt thirsty all the time.

I was then taken into hospital. I had to learn so many things, like a complete new way of life. I had to learn my new diet, I had to learn how to inject myself, and test my urine and my blood. I felt very sad but I started feeling a bit better after a few days. I thought I only had to do all those tests etc while I was in hospital. I didn't realise I had to do them for the rest of my life.

I came out of hospital two days before Xmas. Things were not too bad at first as Mummy had bought me some diabetic sweets so I did not feel left out of things. I also felt quite important because I could do injections like a nurse, and none of my friends could do that.

After a couple of weeks, I started to have 'hypo's' quite a lot and they used to frighten me, and my Mum, and also my friends. I used to follow my Mum all day and I would not let her out of my sight.

I had to have my insulin altered all the time. I did not get much better so I was taken into hospital at 10pm one night. I was frightened. I was allowed out the next day, so it wasn't too bad.

I started having 'hypo's' again and I began to get thirsty and feel ill again, so I was taken back into hospital.

I thought I was going to be in hospital for a long time because they kept taking a lot of blood from me. I was allowed out after five days.

When it was time for me to go back to school, I did not want to go back, because I had been away from school for so long that I was afraid the children would call me 'a mitcher' like they usually do. I was also feeling tired and miserable, and I just could not be bothered to go. My Mum tried to make me go but I decided to run away instead. I also felt that I wanted to die. I ran out the front door and walked around just thinking about myself. I thought that my Mum did not care about me and that nobody cared about me. I decided to go home as I nearly got lost. When I got home my Mum had asked the health visitor to come and see me. I was rude to the health visitor and my Mum as I felt they were being cruel to me. Afterwards when I had calmed down, I was very ashamed of myself, and I went back to school in the afternoon and I enjoyed myself.

I feel normal now, and injections do not bother me now. Sometimes I do not feel like injecting myself but I still go and do it.

I had a 'hypo' last night, but I was very calm and I got over it very quickly.

Amanda Evans (Aged $101 / 2$ years) 